\title{
Life cycle assessment of ocean energy technologies
}

\author{
Andreas Uihlein ${ }^{1}$ \\ Received: 15 June 2015 / Accepted: 18 April 2016 / Published online: 28 April 2016 \\ (C) The Author(s) 2016. This article is published with open access at Springerlink.com
}

\begin{abstract}
Purpose Oceans offer a vast amount of renewable energy. Tidal and wave energy devices are currently the most advanced conduits of ocean energy. To date, only a few life cycle assessments for ocean energy have been carried out for ocean energy. This study analyses ocean energy devices, including all technologies currently being proposed, in order to gain a better understanding of their environmental impacts and explore how they can contribute to a more sustainable energy supply.

Methods The study followed the methodology of life cycle assessment including all life cycle steps from cradle to grave. The various types of device were assessed, on the basis of a functional unit of $1 \mathrm{kWh}$ of electricity delivered to the grid. The impact categories investigated were based on the ILCD recommendations. The life cycle models were set up using detailed technical information on the components and structure of around 180 ocean energy devices from an in-house database.

Results and discussion The design of ocean energy devices still varies considerably, and their weight ranges from 190 to $1270 \mathrm{t}$, depending on device type. Environmental impacts are closely linked to material inputs and are caused mainly by mooring and foundations and structural components, while
\end{abstract}

Responsible editor: Christian Bauer

Electronic supplementary material The online version of this article (doi:10.1007/s11367-016-1120-y) contains supplementary material, which is available to authorized users.

Andreas Uihlein

andreas.uihlein@ec.europa.eu

1 Institute for Energy and Transport, Joint Research Centre, European Commission, P.O. Box 2, 1755 ZG Petten, The Netherlands impacts from assembly, installation and use are insignificant for all device types. Total greenhouse gas emissions of ocean energy devices range from about 15 to $105 \mathrm{~g} \mathrm{CO}_{2}$-eq. $\mathrm{kWh}^{-1}$. Average global warming potential for all device types is 53 $\pm 29 \mathrm{~g} \mathrm{CO}_{2}$-eq. $\mathrm{kWh}^{-1}$. The results of this study are comparable with those of other studies and confirm that the environmental impacts of ocean energy devices are comparable with those of other renewable technologies and can contribute to a more sustainable energy supply.

Conclusions Ocean energy devices are still at an early stage of development compared with other renewable energy technologies. Their environmental impacts can be further reduced by technology improvements already being pursued by developers (e.g. increased efficiency and reliability). Future life cycle assessment studies should assess whole ocean energy arrays or ocean energy farms.

Keywords Device type $\cdot$ Horizontal axis turbine $\cdot$ Ocean energy $\cdot$ Point absorber · Tidal energy $\cdot$ Wave energy

\section{Introduction}

The world's oceans and seas are an abundant source of various forms of renewable energy. According to Falcão (2010) and Esteban and Leary (2012), six types of ocean energy can be distinguished: ocean wave, tidal range, tidal current, ocean current, ocean thermal energy and salinity gradient. In this paper, we focus on ocean wave and tidal current, which represent a potentially significant source of electricity in Europe (Magagna and Uihlein 2015). The corresponding energy industries have made considerable progress in recent years but are still at an early stage of development (Magagna and Uihlein 2015). A number of technologies are nearing the pre-commercial array 
demonstration stage, and others are being deployed in full-scale prototypes in real-sea environments (Magagna and Uihlein 2015).

As a form of renewable energy, ocean energy can contribute to a more sustainable energy supply, but it is not environmentally friendly per se. The activities involved in the manufacture, operation, maintenance and decommissioning of ocean energy devices will have various effects on the environment. However, only a few life cycle assessments (LCAs) of individual wave and tidal energy converters have been performed to date, with a main focus on devices at an advanced stage of development (Magagna and Uihlein 2015). Most studies (e.g. Parker et al. 2007; Douglas et al. 2008; Walker and Howell 2011) have looked only at energy and carbon as impact categories. According to Uihlein and Magagna (2015), good quality studies are lacking, especially for tidal current, ocean thermal energy and salinity gradient devices, and further LCA studies are needed to produce more estimates for all ocean energy technologies. For a number of wave energy device types, such as point absorbers and attenuators (the most common types), there are no LCA studies at all.

The European Commission's Joint Research Centre (JRC) has developed an ocean energy database which contains detailed technical information on 186 wave and tidal energy devices that have been tested or deployed in real-water conditions (Uihlein et al. 2015). In this paper, we assess the environmental impacts of eight types of wave energy and seven types of tidal energy devices on the basis of information in the JRC database. The remainder of the paper is structured as follows: In Section 2, we present our methodology, including goal and scope definition, functional unit and system boundaries. Section 3 gives an overview of the data, information and assumptions used to establish the LCA model. Section 4 sets out the results. Discussions and conclusions can be found in Section 5.

\section{Methods}

\subsection{Goal and scope definition}

The goal of the study is to assess the environmental impacts of various ocean energy devices producing electricity and delivering it to the European electricity network. The LCA is performed at aggregate level for tidal energy and wave energy device types, rather than on individual devices at a specific site. The study will help to identify variations between ocean energy device types with respect to environmental impacts, to identify the most important life cycle stages of ocean energy devices in terms of environmental impacts and to understand differences between wave and tidal devices.

\subsection{Functional unit and system boundaries}

The functional unit of the study is $1 \mathrm{kWh}$ of electricity delivered to the European electricity network. The LCA encompasses all life cycle steps 'from cradle to grave', including device assembly, installation, use and end of life, as recommended in Raventos et al. (2010). Apart from the device itself (Section 3.1), it also covers mooring and foundations and the cable connection to the grid (Section 3.2). The study assumes deployment in Europe but takes account of worldwide upstream and downstream emissions and resource inputs (Section 2.3). Assumed device lifetime is 20 years. The life cycle of an ocean energy device is shown schematically in Fig. 1.

\subsection{Life cycle impact assessment and interpretation}

The life cycle impact assessment was performed at midpoint level and follows the recommendation in Hauschild et al. (2012). All impact categories rated levels II and III in Hauschild et al. (2012) have been included in this study (Table 1).

\section{Life cycle inventory data}

The GaBi v6.4 LCA software was used to model the system (Eyerer 1996; Thinkstep 2015a). Most of the primary data used stems from the JRC ocean energy database, while secondary data has mainly been retrieved from the GaBi professional database (Thinkstep 2015b). Below, we give a detailed description of the life cycle inventory and data sources used for modelling.

The JRC database includes information on tidal and wave energy devices that have been tested or deployed in real-water conditions. In addition, it contains information on tidal and wave energy projects in which such devices were used (Uihlein et al. 2015). In total, the database covers 83 tidal devices from 36 developers and 103 wave devices from 50 developers. These were all released after 1995 , over $75 \%$ after 2007 and over $50 \%$ after 2010. They can be classified into seven tidal and eight wave energy device types (Magagna and Uihlein 2015). Figures 2 and 3 show a breakdown of the devices according to type. For some types (e.g. Archimedes screw, overtopping device), not many devices have been tested in real-water conditions, while others can be found more often: for example, the database contains 49 horizontal and 7 vertical axis turbines (tidal energy devices), 53 point absorbers and 16 oscillating wave surge converters (wave energy devices). For tidal energy converters, a design consensus seems to emerge in favour of horizontal axis turbines (Magagna and Uihlein 2015). 


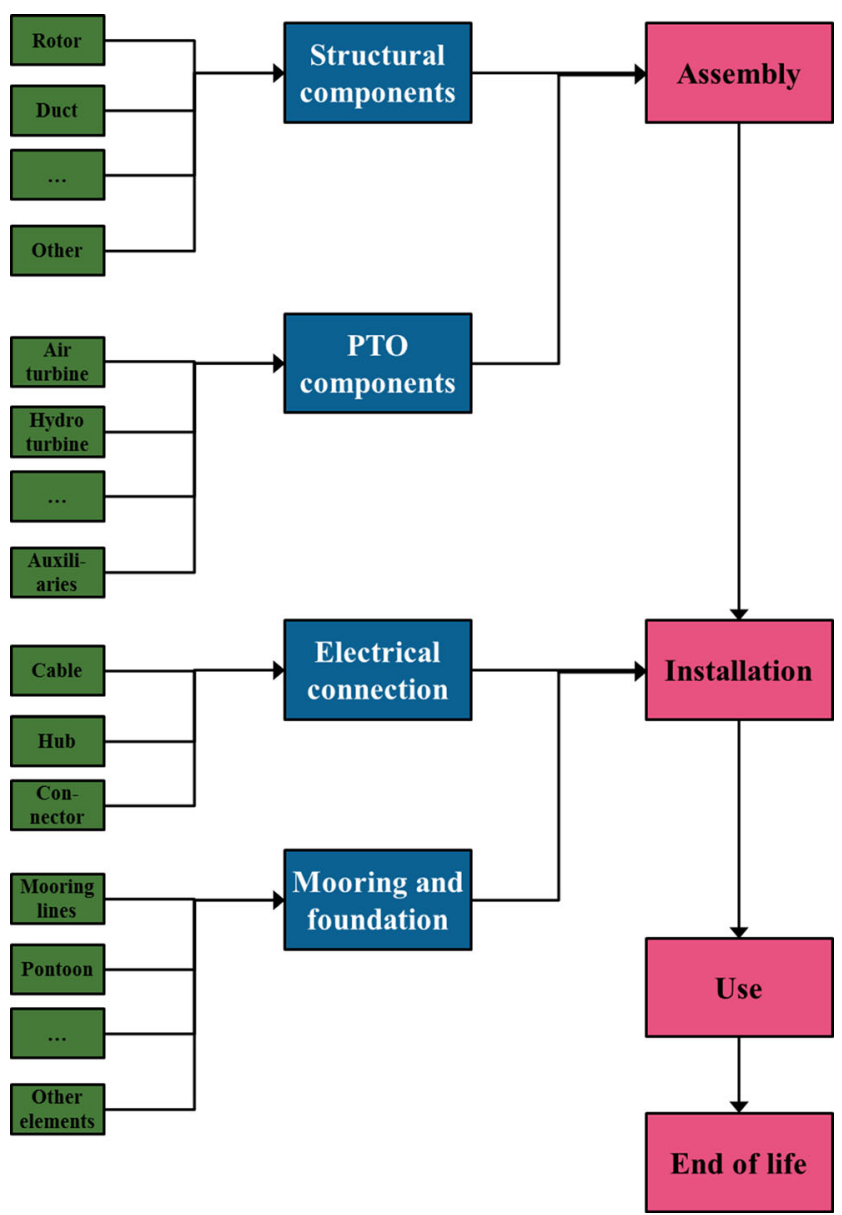

Fig. 1 Schematic life cycle of an ocean energy device. Pink: life cycle step, blue: component, green: sub-component

\subsection{Device-specific data}

At device level, the database hosts technical information on structural components and sub-components, such as numbers, weight, dimensions and materials. In addition, it contains information such as device type and developer, power rating, release year, technology readiness level and technical information (e.g. rotor speeds, blade tip speeds, pitch angles, freeboard). The type of technical information and the parameters for structural components are shown in Table A1 (Electronic supplementary material).

\subsubsection{Structural components}

Device types differ considerably in terms of design and structural components. Some components are found in certain device types only and are not applicable or not used for others. Figure 4 shows an example of the structural components of tidal devices in the database according to device type. The most common structural component is a rotor, as these are used in the most common device types (horizontal axis turbines, vertical axis turbines and enclosed-tip devices). Some components, such as pods or ballast, are used more rarely.

In many cases, data gaps exist in the database because information was unavailable or not disclosed by a developer for reasons of confidentiality. Various assumptions and estimates were made in order to fill the gaps (Table C1, Electronic supplementary material). In general, component mass was estimated on the basis of dimensions and average database values, and it was assumed that the most common material type was used in each case. For horizontal axis turbines and point absorbers, for example, about $90 \%$ of the input parameters for calculating the mass of the structural components had to be based on average data. More importantly, however, we performed sensitivity analyses to assess the influence of these uncertainties and identified the most significant parameters determining the LCA results (Section 4.3).

\subsubsection{Power take-off and related components}

We also retrieved from the database information on power take-off (PTO) and related components, including data on turbine, shaft, gearbox, generator, control systems, frequency converter and auxiliary systems. The type of technical information and the PTO parameters are shown in Table A2 (Electronic supplementary material). Data gaps were filled in the same way as for structural components (Table C2, Electronic supplementary material).

\subsection{Project-specific data}

The type of mooring and foundation used for individual devices and the electrical connection, installation and maintenance depend on the individual project in which the device is deployed.

\subsubsection{Mooring and foundations}

Of the types of mooring and foundation used for the projects in the database (see Table B1, Electronic supplementary material), foundations were by far the most used, followed by moorings and anchors. Mooring and foundation information was used where available. If devices had been deployed in several projects, we used the mooring and foundation information from the most recent project (assuming that commercial deployment equates to more realistic conditions of use). For devices for which there was no information, we calculated and assumed the average of all mooring and foundations used in projects involving the device type in question (Table C3, Electronic supplementary material). 
Table 1 Life cycle impact assessment methods used in this study

\begin{tabular}{|c|c|c|c|c|}
\hline Impact category & Short name & LCIA method & Indicator & Unit \\
\hline Climate change & Global warming & IPCC baseline model & Global warming potential & $\mathrm{kg} \mathrm{CO}_{2}$ eq. \\
\hline Acidification & Acidification & Accumulated exceedance & Accumulated exceedance & Mole of $\mathrm{H}+$ eq. \\
\hline Ozone depletion & Ozone depletion & WMO model & Ozone depletion potential & kg CFC-11 eq. \\
\hline Particulate matter/respiratory inorganics & Particulate matter & RiskPoll model & Fine particles & $\mathrm{kg} \mathrm{PM}_{2.5}$ eq. \\
\hline Ionising radiation, human health & Ionising radiation & Human health effect model & Human exposure & $\mathrm{kg} \mathrm{U} 235$ eq. \\
\hline Human toxicity, cancer effects & Human tox. cancer & USEtox model & Comparative toxic units & CTUh \\
\hline Human toxicity, non-cancer effects & Human tox. non-cancer & USEtox model & Comparative toxic units & CTUh \\
\hline Photochemical ozone formation & Summer smog & LOTOS-EUROS model & Ozone concentration increase & kg NMVOC \\
\hline Freshwater eutrophication & Freshwater eutroph. & EUTREND model & Nutrients reaching end compartment & $\mathrm{kg} P$ eq. \\
\hline Marine eutrophication & Marine eutroph. & EUTREND model & Nutrients reaching end compartment & $\mathrm{kg} \mathrm{N}$ eq. \\
\hline Terrestrial eutrophication & Terrestrial eutroph. & Accumulated exceedance & Accumulated exceedance & $\mathrm{kg} \mathrm{N}$ eq. \\
\hline Freshwater ecotoxicity & Freshwater ecotox. & USEtox model & Comparative toxic units & CTUh \\
\hline Resource depletion, fossil and mineral & Resource depletion & CML2002 reserve based & Scarcity & $\mathrm{kg} \mathrm{Sb}$ eq. \\
\hline
\end{tabular}

\subsubsection{Electrical connection}

Not all the projects in the database were grid connected. The electrical connection was modelled using three parts: cable, connector and hub (Table B1, Electronic supplementary material). We assumed a $33-\mathrm{kV}$ AC transmission cable (Lopez et al. 2010) with an assumed weight of $20 \mathrm{~kg} / \mathrm{m}$ (Anonymous 2011). Electrical losses from the connection were not considered in this study. Cable length was retrieved from the database; if it was unavailable, we assumed the average value $(2980 \mathrm{~m})$. For connector and hub, we assumed a weight of 5000 . No substations were included in this study.

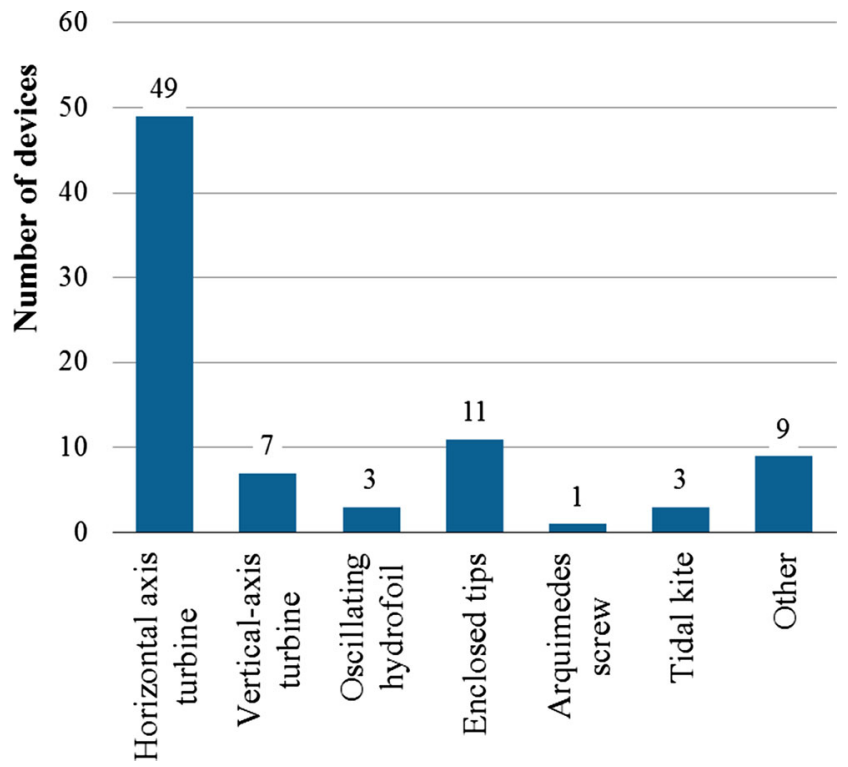

Fig. 2 Number of tidal energy devices in the database according to device type
In some cases, additional electricity networks have to be built and the existing grid has to be upgraded or reinforced when ocean arrays are deployed in remote areas with weaker grids (Magagna and Uihlein 2015). Such upgrades have not been included in this study.

\subsubsection{Installation and maintenance}

The database includes records of maintenance and installation operations carried out in the course of ocean energy projects. These include duration and vessel types used. If no information was available, we used average values ( $26 \mathrm{~h}$ for installation and $100 \mathrm{~h}$ maintenance per year).

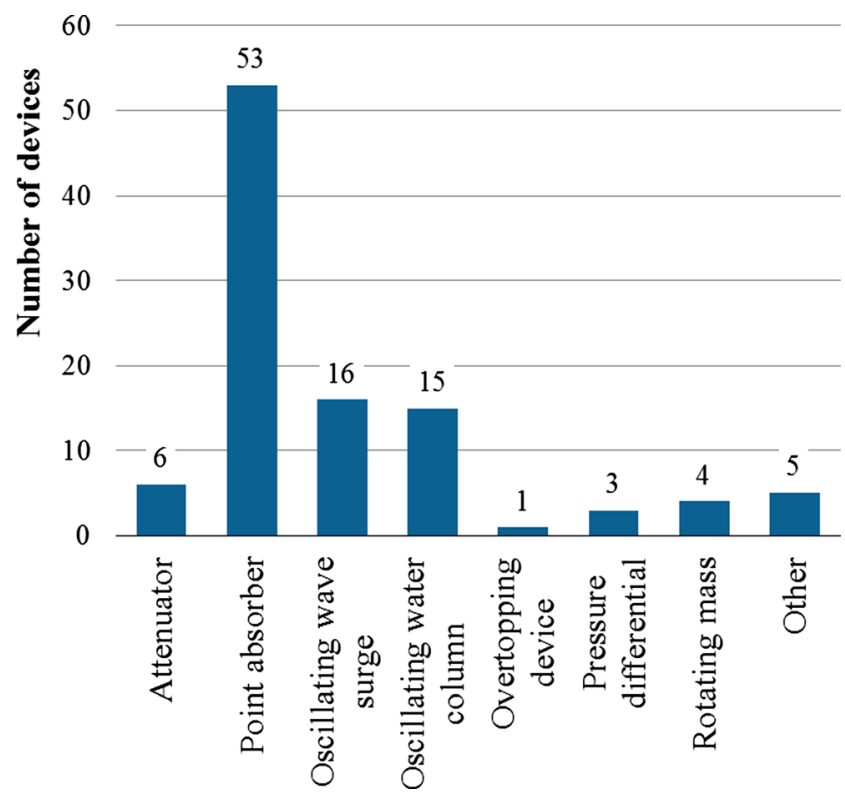

Fig. 3 Number of wave energy devices in the database according to device type 


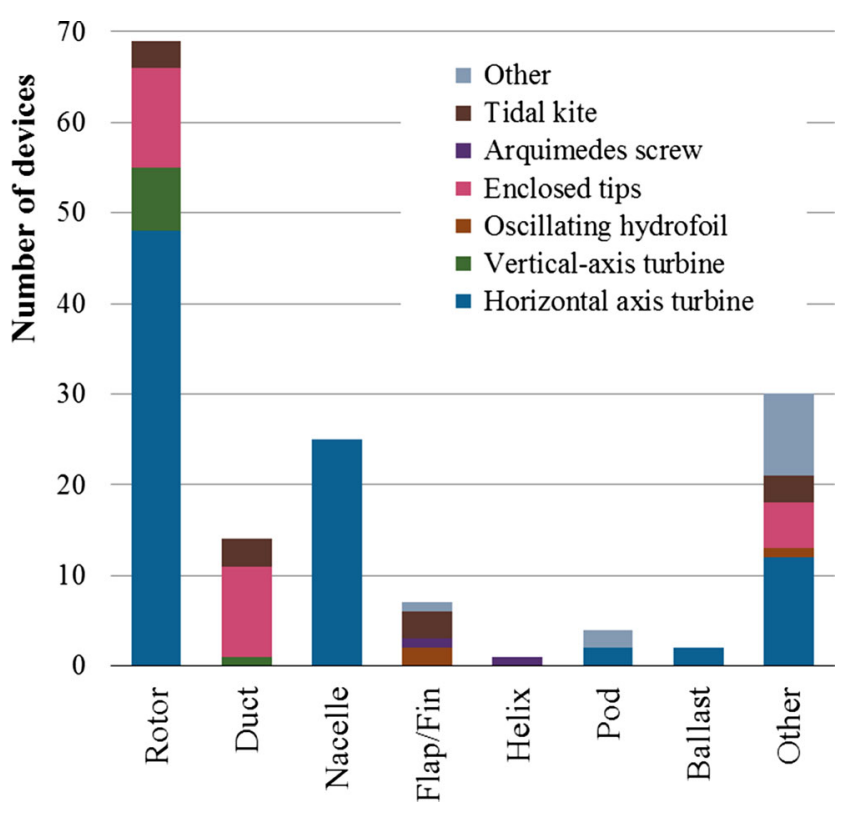

Fig. 4 Structural components of tidal devices in the database

We assumed that $70 \%$ of the operations are executed using a vessel and $30 \%$ using a barge.

As deployment of ocean energy devices has been limited to date, the database provides no information on replacement parts and replacement intervals. Following the example of previous studies (Parker et al. 2007; Thomson et al. 2011; Dalton et al. 2014), we assumed that no parts have to be replaced.

\subsection{Power output}

Electricity production was calculated using the nominal capacity of the devices. Reported capacities range from 0.07 to $3000 \mathrm{~kW}$, with the majority of devices having a nominal capacity between 500 and $1000 \mathrm{~kW}$ (Fig. 5).

We assumed capacity factors of $34 \%$ for tidal and $20 \%$ for wave energy devices, which is in the range of values given by Esteban and Leary (2012).

\subsection{LCI data and assumptions for upstream and downstream processes}

\subsubsection{Upstream datasets - materials and energy}

For materials and energy carriers used to produce structural and PTO components, electrical connections and mooring and foundations, we used secondary data from databases, mainly from Thinkstep (2015b) (Table 2). We performed a sensitivity analysis as regards the type of steel assumed in the model (Section 4.3).

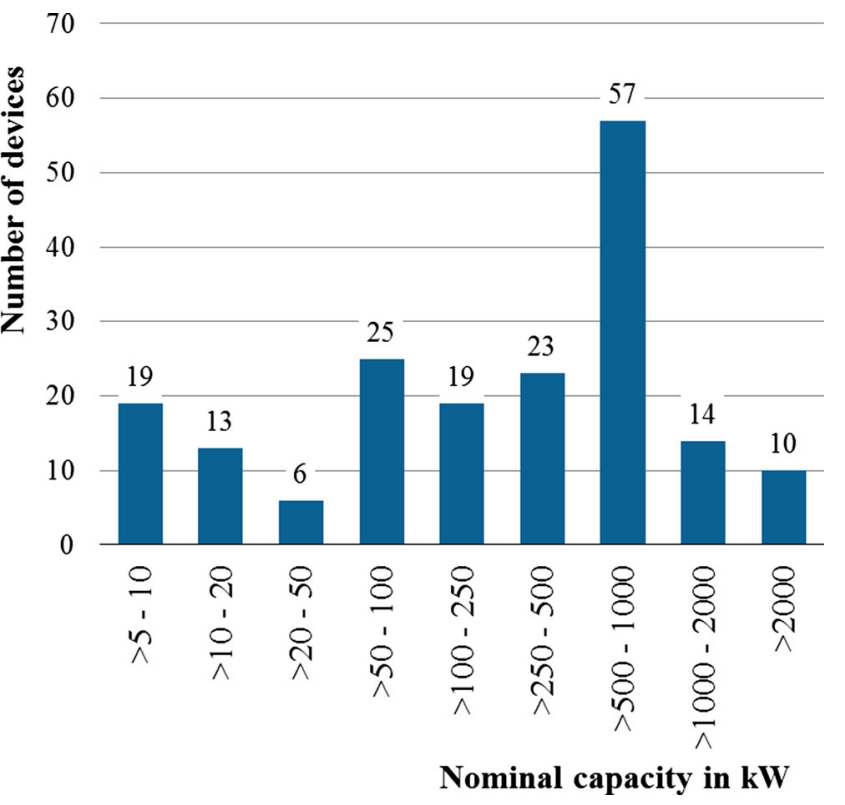

Fig. 5 Nominal capacity of ocean energy devices in the database

\subsubsection{Assembly and manufacturing}

We modelled device assembly assuming an electricity input of approximately $1.5 \mathrm{kWh} / \mathrm{kg}$ with an assumed electrical energy/ heat ratio of 2:1 (Sullivan et al. 2013) ${ }^{1}$ for the assembly of structural components, PTO components, mooring and foundations and the electrical connection.

Manufacturing processes for structural components (e.g. plastics injection moulding, steel sheet deep drawing, aluminium cast machining) were modelled using $\mathrm{GaBi}$ datasets (Thinkstep 2015b).

\subsubsection{Transports}

All transport was assumed to be by lorry (EU-27: articulated lorry transport). We assumed a distance of $500 \mathrm{~km}$ for the transport of structural and PTO components to the point of assembly and of the material for electrical connections and mooring and foundations to the harbour from which installation is carried out.

We assumed a distance of $1000 \mathrm{~km}$ for the transport of subcomponents to the point where the components are assembled (e.g. rotor to the point of assembly of the structural components) and of upstream materials from the place of production to the place of sub-component manufacturing (e.g. transport of steel to the location where the rotor is built).

We did not include transport of the fully assembled device to the harbour since we assumed that it would be assembled at the harbour and transport distance would be negligible. We

\footnotetext{
${ }^{1}$ Energy demand of machining, HVAC and lighting, heating and material handling according to Sullivan et al. (2013) have been included.
} 
Table 2 Datasets used for materials and energy carriers

\begin{tabular}{lll}
\hline Material & Dataset used & Source \\
\hline Steel & RER: stainless steel Quarto plate (316) & Thinkstep (2015b) \\
Plastic & DE: polycarbonate granulate (PC) & Thinkstep (2015b) \\
Composites & DE: sheet moulding compound resin mat (SMC) & Thinkstep (2015b) \\
Aluminium & EU-27: aluminium ingot mix & Thinkstep (2015b) \\
Water & EU-27: tap water & Thinkstep (2015b) \\
Copper & DE: copper mix (99.999 \% from electrolysis) & Thinkstep (2015b) \\
Electronics & Modelled according to electronic component & Heck (2007) \\
Lead & EU-27: lead primary and secondary mix ILA & Thinkstep (2015b) \\
PVC & RER: polyvinylchloride injection moulding part & Thinkstep (2015b) \\
PE pipe & RER: polyethylene pipe (PE-HD) & Thinkstep (2015b) \\
Tin & RER: tin, at regional storage & Ecoinvent (2007) \\
Platinum & RER: platinum, at regional storage & Ecoinvent (2007) \\
Nickel & GLO: nickel, $99.5 \%$, at plant & Ecoinvent (2007) \\
Concrete & CN: prefabricated concrete part slab, 40 cm & Thinkstep (2015b) \\
Electricity & EU-27: electricity grid mix & Thinkstep (2015b) \\
Heat & EU-27: thermal energy from natural gas & Thinkstep (2015b) \\
Light fuel oil & EU-27: light fuel oil at refinery & Thinkstep (2015b) \\
\hline
\end{tabular}

included transport of $1000 \mathrm{~km}$ to the final disposal site (landfill, incineration) after use.

The results show that the environmental impacts of transport are negligible as compared with other life cycle steps (Section 4.2) so the very generic assumptions on transport distances and means are justified.

\subsubsection{Installation and maintenance}

For installation and maintenance operations, the use of vessels and barges was modelled as described in Section 3.2.3. We used the 'GLO: bulk commodity carrier' and 'EU-27: barge incl. fuel' datasets (Thinkstep 2015b).

\subsubsection{End of life}

For modelling the end of life (EOL) of the ocean energy devices, we assumed no environmental impacts from disassembly processes. We assumed three different EOL routes for materials used-recycling, incineration and landfilling (Table 3) taking the proportional breakdown from Zimmermann (2012).

Since no one has any real experience of disposal of ocean energy devices, this can be considered a rough estimate. For the majority of materials (e.g. steel and other metals), the recycling quota could probably be higher. We applied no credits for recycling. For landfilling and incineration, we used the relevant datasets from Thinkstep (2015b). A credit was applied for energy recovery from incineration and recycling, using the datasets from Table 2 for electricity and heat.

\section{Results}

\subsection{Mass flows}

Figure 6 shows the average volume of material used to produce the device. Device weights vary considerably between device types: from about 190,000 kg for enclosed-tip devices to $1,270,000 \mathrm{~kg}$ for overtopping devices. On average, tidal device types have a lower mass than wave energy devices.

For most device types, mooring and foundations contribute most to total device weight. For 12 types, the proportion is over $50 \%$ and it can reach $86 \%$ in the case of the vertical axis turbine. Structural components are also important, making up an average $26 \%$ of the total weight. PTO components account for a relatively minor proportion (less than $10 \%$ for 10 device types), but this can reach $36 \%$ in the case of attenuators. The electrical connection contributes less than $10 \%$ in all device types except oscillating hydrofoils.

We also calculated the specific mass of device types in terms of kilograms per kilowatt nominal capacity. Here, the difference between tidal and wave energy devices is small (Fig. 7). Specific weights range from about $470 \mathrm{~kg} \mathrm{~kW}^{-1}$ for enclosed-tip to about $3860 \mathrm{~kg} \mathrm{~kW}^{-1}$ for rotating mass devices. Interestingly, the relative weight contribution of structural components is much higher in wave energy devices than in tidal energy devices (38 and $12 \%$, respectively).

As regards the mass of material used, we found that steel predominates. For all device types except overtopping devices, steel accounts for over $45 \%$ of total weight (Table 4 ). Concrete is an important material in overtopping devices 
Table 3 Assumptions and datasets for EOL

\begin{tabular}{llll}
\hline Material & Recycling (\%) & Incineration (\%) & Landfill (\%) \\
\hline Ferrous metals & 90 & 0 & 10 \\
Non-ferrous metals & 95 & 0 & 5 \\
Plastics & 80 & 20 & 0 \\
Composites & 0 & 100 & 0 \\
Concrete & 85 & 0 & 15 \\
Sand & 0 & 0 & 0 \\
Electronics & 0 & 100 & 0 \\
\hline
\end{tabular}

Source: Zimmermann (2012)

${ }^{\text {a } U s e d ~ o n l y ~ a s ~ b a l l a s t, ~ a s s u m e d ~ t o ~ r e m a i n ~ o n ~ t h e ~ s e a b e d ~ a f t e r ~ u s e ~}$

(about $55 \%$ ) and makes up between about 20 and $30 \%$ of the weight of eight device types. Proportions of other metals (aluminium, iron, copper) and plastics can go up to $13 \%$ but in general are less than $10 \%$. Electronics make up no more than $4 \%$.

\subsection{LCA results: base case}

A wealth of LCA results was obtained from the model calculations. We will look first at the environmental impacts of the most prevalent device types, i.e. horizontal axis turbine for tidal energy and point absorber for wave energy devices.

The environmental impacts of horizontal axis turbines are shown in Fig. 8. The individual components are displayed separately, while the processes for device assembly and installation have been grouped together. For almost all impact

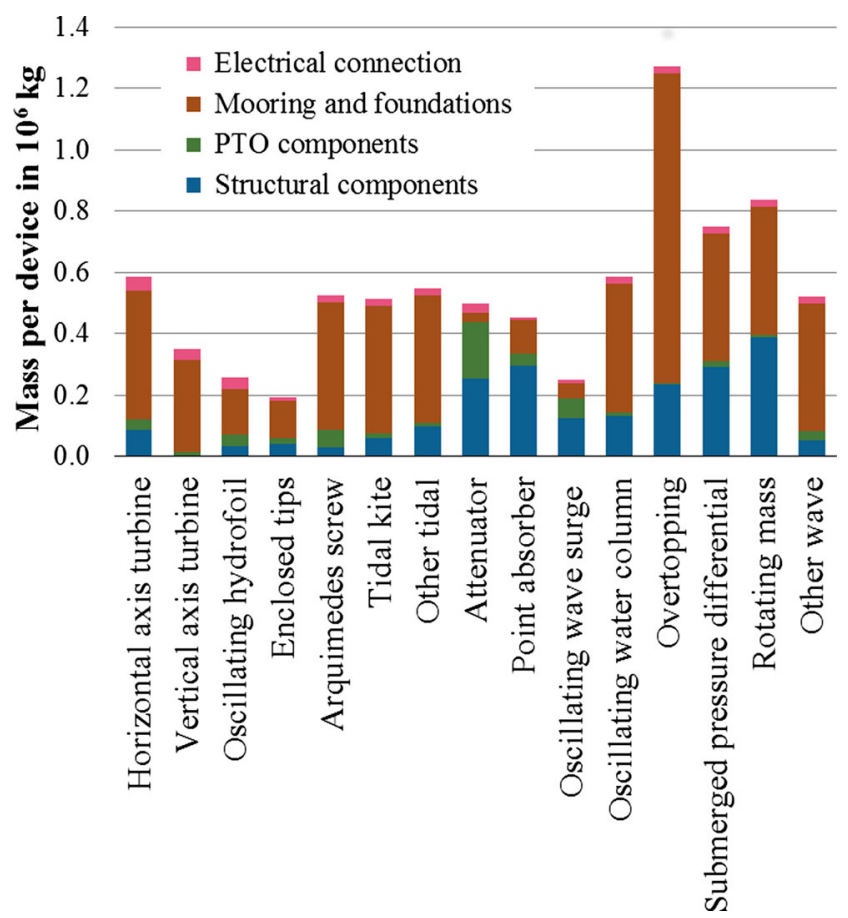

Fig. 6 Amount of materials for the production of ocean energy devices

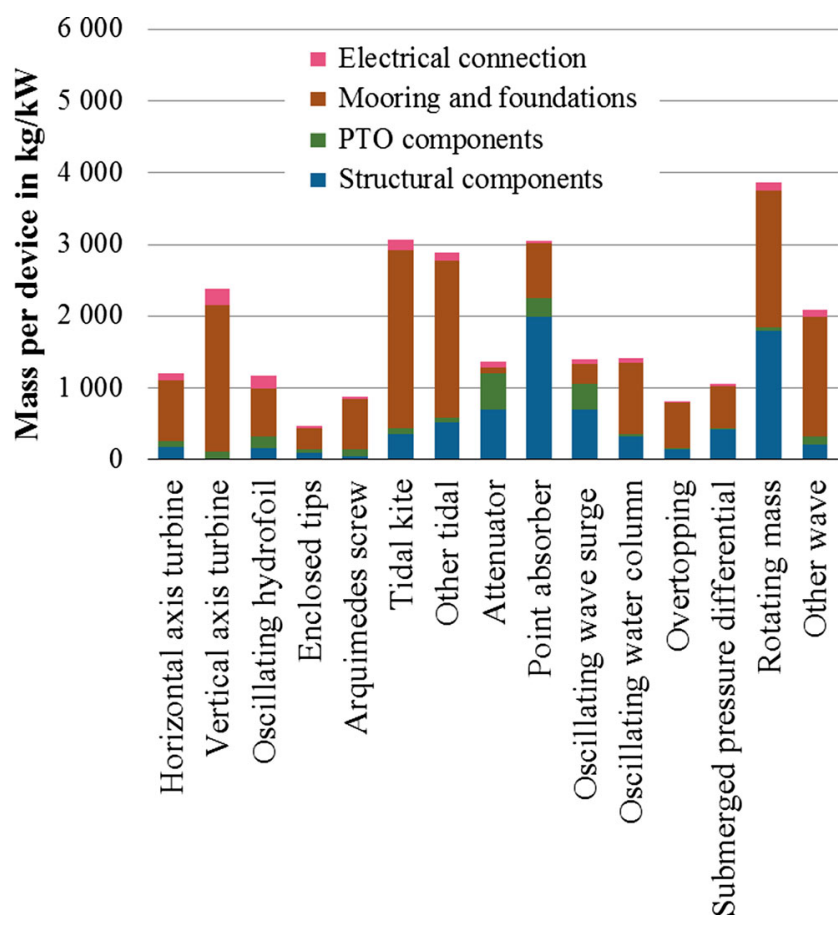

Fig. 7 Amount of materials for the production of ocean energy devices

categories, mooring and foundations contribute the most environmental impacts. Depending on impact category, the electrical connection and PTO components account for significant proportions (over $25 \%$ ). Structural components and end of life contribute very little, while assembly, installation and use do not produce significant impacts.

Figure 9 shows the (somewhat different) results for point absorbers. Clearly, structural components dominate the environmental impacts; they account for over $40 \%$ in all but two impact categories. Next, mooring and foundations but also PTO components (in two impact categories) play a significant role. Again, the impacts from assembly, installation and use are not significant.

The LCA results for these two device types closely reflect the relative contributions of the various components to the overall weight of the device as shown in Fig. 7. We analysed the correlation between the volume of material used per component (structural components, PTO components, electrical connection, mooring and foundations) and the environmental impacts per component (including end of life). As shown in Table 5, environmental impacts are closely related to mass flows. For almost all impact categories except ionising radiation and freshwater eutrophication, there are positive correlations between component mass and the environmental impacts. Correlation coefficients are greater than $60 \%$ for the majority of impact categories and ocean energy devices.

Freshwater eutrophication impacts are dominated by some materials that have disproportionately high specific impacts: polycarbonate, copper (used for cables in the electrical connection) and stainless steel, which is used mainly in mooring 
Table 4 Share of material used to produce ocean energy device in \% of total weight

\begin{tabular}{|c|c|c|c|c|c|c|c|}
\hline Device type & Steel & Other metals & Electronics & Plastics $^{\mathrm{a}}$ & Concrete & Sand & Water \\
\hline Horizontal axis turbine & 50.24 & 6.38 & 0.86 & 6.98 & 32.69 & 0.78 & 2.07 \\
\hline Vertical axis turbine & 88.40 & 5.52 & 1.47 & 4.60 & 0.00 & 0.00 & 0.00 \\
\hline Oscillating hydrofoil & 76.99 & 9.70 & 1.81 & 11.21 & 0.30 & 0.00 & 0.00 \\
\hline Enclosed tips & 77.82 & 8.02 & 2.85 & 10.86 & 0.45 & 0.00 & 0.00 \\
\hline Archimedes screw & 54.52 & 12.52 & 0.34 & 7.59 & 25.03 & 0.00 & 0.00 \\
\hline Tidal kite & 64.28 & 2.62 & 1.54 & 5.59 & 25.98 & 0.00 & 0.00 \\
\hline Other tidal & 64.49 & 3.28 & 0.57 & 7.14 & 24.53 & 0.00 & 0.00 \\
\hline Attenuator & 46.20 & 7.04 & 1.03 & 6.56 & 6.30 & 8.96 & 23.90 \\
\hline Point absorber & 50.36 & 3.80 & 0.94 & 11.98 & 13.60 & 5.27 & 14.05 \\
\hline Oscillating wave surge & 55.01 & 7.93 & 3.03 & 12.97 & 8.33 & 3.47 & 9.25 \\
\hline Oscillating water column & 60.62 & 3.14 & 0.59 & 4.01 & 31.63 & 0.00 & 0.00 \\
\hline Overtopping & 36.73 & 0.93 & 0.15 & 0.92 & 55.48 & 1.58 & 4.21 \\
\hline Submerged pressure differential & 63.11 & 3.37 & 0.93 & 11.22 & 21.29 & 0.02 & 0.05 \\
\hline Rotating mass & 46.11 & 2.81 & 0.34 & 4.87 & 20.56 & 6.90 & 18.40 \\
\hline Other wave & 65.51 & 3.63 & 0.54 & 4.76 & 25.56 & 0.00 & 0.00 \\
\hline
\end{tabular}

${ }^{\mathrm{a}}$ Includes also composites

and foundations (e.g. piles). High ionising radiation impacts stem from the electricity demand of manufacturing processes (e.g. production of electronics, assembly process). Resource depletion impacts are linked mainly to copper and steel.

We also quantified the proportion of environmental impacts stemming from transport processes. For both horizontal axis turbines and point absorbers, this is not significant. For no

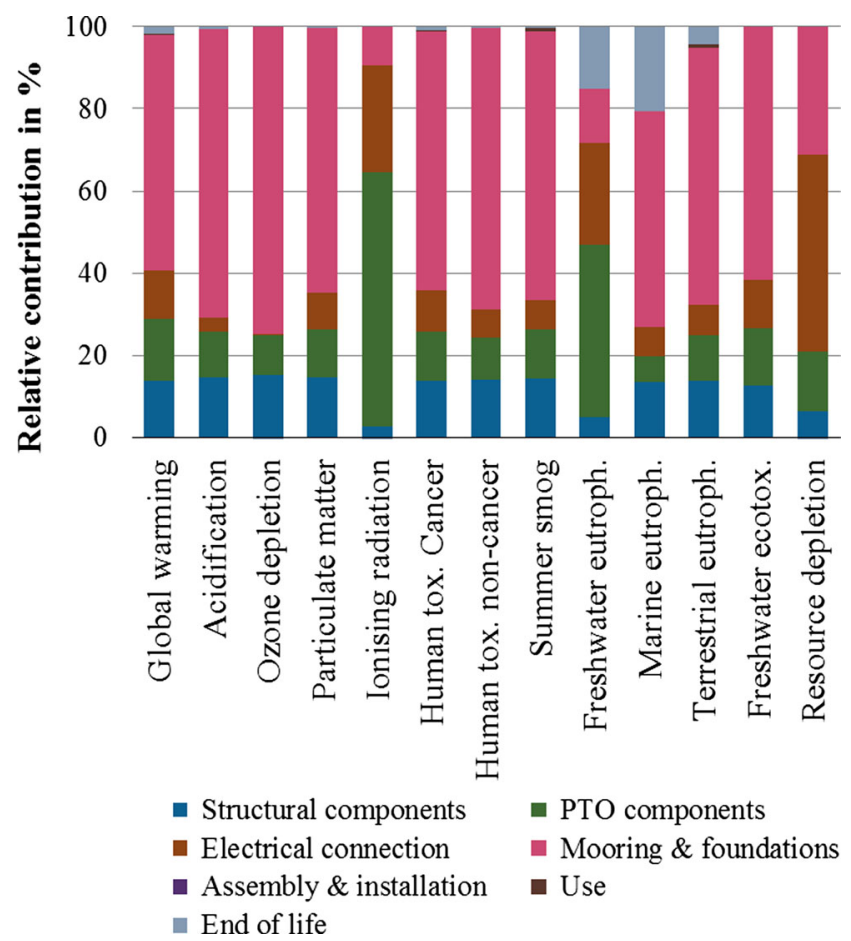

Fig. 8 Environmental impacts of horizontal axis turbines according to life cycle step impact category do the impacts from transport exceed $0.2 \%$ of total impacts.

Since ocean energy is considered by many as a technology that will contribute to a low-carbon energy system, we looked in detail at the LCA results for global warming. Figure 10 shows the global warming potential (GWP) of device types according to life cycle step. Total greenhouse gas (GHG)

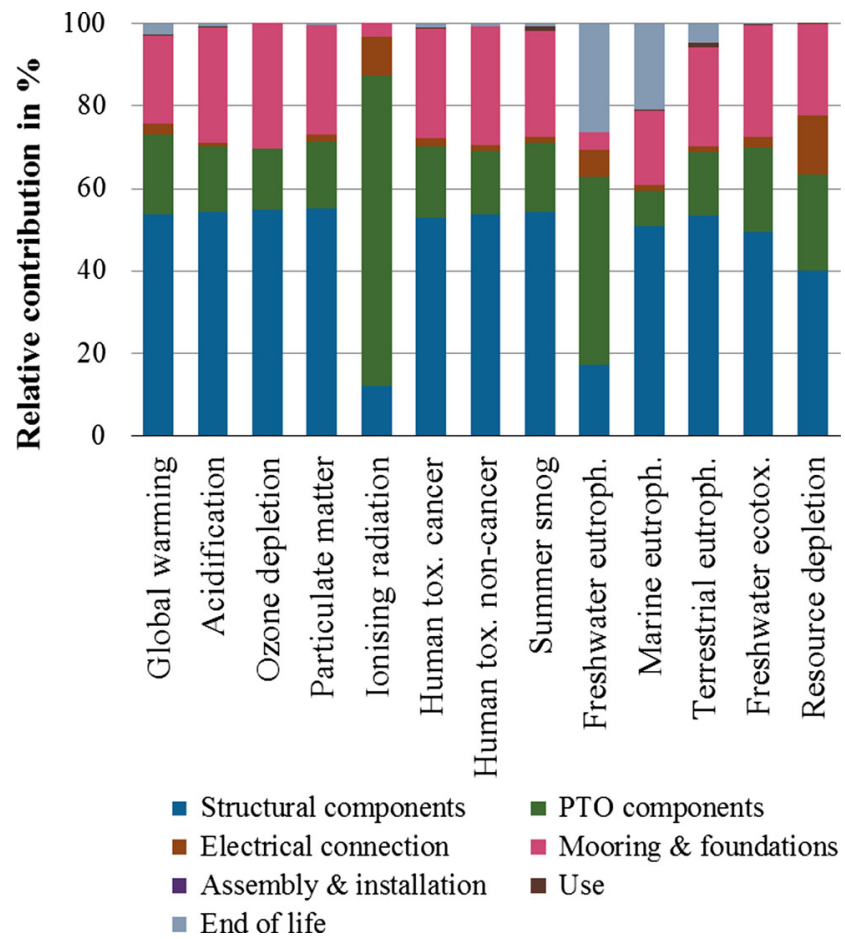

Fig. 9 Environmental impacts of point absorber according to life cycle step 
Table 5 Correlation between environmental impacts and device mass per life cycle step

\begin{tabular}{|c|c|c|c|c|c|c|c|c|c|c|c|c|c|c|c|}
\hline Impact category & HAT & VAT & $\mathrm{OHF}$ & ETP & AQS & TKT & TOT & ATT & PTA & OWS & OWC & OVT & SPD & RMA & WOT \\
\hline Global warming & 0.99 & 1.00 & 0.98 & 0.93 & 1.00 & 0.98 & 1.00 & 0.68 & 0.97 & 0.80 & 0.99 & 0.99 & 0.98 & 0.94 & 1.00 \\
\hline Acidification & 0.99 & 1.00 & 0.98 & 0.99 & 1.00 & 1.00 & 1.00 & 0.60 & 0.98 & 0.87 & 1.00 & 0.98 & 1.00 & 0.89 & 1.00 \\
\hline Ozone depletion & 0.99 & 0.99 & 0.97 & 0.99 & 1.00 & 1.00 & 1.00 & 0.57 & 0.98 & 0.88 & 1.00 & 0.97 & 1.00 & 0.87 & 1.00 \\
\hline Particulate matter & 1.00 & 1.00 & 1.00 & 0.99 & 1.00 & 1.00 & 1.00 & 0.60 & 0.99 & 0.88 & 1.00 & 0.98 & 1.00 & 0.90 & 1.00 \\
\hline Ionising radiation & -0.24 & -0.18 & -0.11 & -0.20 & 0.13 & -0.25 & -0.20 & 0.41 & -0.14 & 0.00 & -0.25 & 0.36 & -0.37 & -0.30 & -0.09 \\
\hline Human tox. cancer & 0.99 & 1.00 & 1.00 & 0.98 & 1.00 & 1.00 & 1.00 & 0.58 & 0.98 & 0.83 & 1.00 & 0.98 & 1.00 & 0.89 & 1.00 \\
\hline Human tox. non-cancer & 1.00 & 1.00 & 0.99 & 0.99 & 1.00 & 1.00 & 1.00 & 0.57 & 0.98 & 0.87 & 1.00 & 0.98 & 1.00 & 0.88 & 1.00 \\
\hline Summer smog & 1.00 & 1.00 & 0.99 & 0.98 & 1.00 & 1.00 & 1.00 & 0.62 & 0.98 & 0.86 & 1.00 & 0.98 & 1.00 & 0.90 & 1.00 \\
\hline Freshwater eutroph. & -0.13 & -0.02 & -0.07 & -0.16 & 0.31 & -0.18 & 0.12 & 0.53 & 0.46 & 0.22 & 0.06 & 0.78 & 0.01 & 0.47 & 0.24 \\
\hline Marine eutroph. & 1.00 & 1.00 & 1.00 & 0.99 & 1.00 & 1.00 & 1.00 & 0.96 & 1.00 & 1.00 & 1.00 & 1.00 & 0.99 & 0.99 & 1.00 \\
\hline Terrestrial eutroph. & 1.00 & 1.00 & 1.00 & 0.99 & 1.00 & 1.00 & 1.00 & 0.70 & 0.99 & 0.90 & 1.00 & 0.99 & 1.00 & 0.93 & 1.00 \\
\hline Freshwater ecotox. & 0.99 & 1.00 & 0.99 & 0.96 & 0.99 & 0.99 & 1.00 & 0.52 & 0.95 & 0.71 & 0.99 & 0.97 & 0.99 & 0.86 & 1.00 \\
\hline Resource depletion & 0.34 & 0.76 & 0.33 & 0.76 & 0.57 & 0.82 & 0.82 & 0.20 & 0.88 & 0.33 & 0.80 & 0.84 & 0.83 & 0.63 & 0.82 \\
\hline
\end{tabular}

$H A T$ horizontal axis turbine; VAT vertical axis turbine; $O H F$ oscillating hydrofoil; $E T P$ enclosed tips; $A Q S$ archimedes screw; TKT tidal kite; TOT other tidal; ATT attenuator; PTA point absorber; $O W S$ oscillating wave surge; $O W C$ oscillating water column; $O V T$ overtopping; $S P D$ submerged pressure differential; RMA rotating mass; WOT other wave

emissions range from about $15 \mathrm{~g} \mathrm{CO}_{2}$-eq. $\mathrm{kWh}^{-1}$ for enclosed-tip devices to about $105 \mathrm{~g} \mathrm{CO}_{2}$-eq. $\mathrm{kWh}^{-1}$ for point absorber and rotating mass devices. The average GWP for all device types is $53 \pm 29 \mathrm{~g} \mathrm{CO}_{2}$-eq. $\mathrm{kWh}^{-1}$.

For almost all device types, mooring and foundations contribute most to GHG emissions (over $40 \%$ for 12 out of 15 device types). With attenuator and oscillating wave surge devices, the PTO components account for the proportion of GHG emissions; with point absorbers, the structural components are responsible for the majority. Electrical connections are not a major source of GHGs; in general, they contribute less than $10 \%$ and are responsible for a significant proportion only in the case of oscillating hydrofoils. The proportions for other life cycle stages (assembly, installation, use and end of life) are almost negligible ( $2.6 \%$ and less) for all device types.

\subsection{LCA results of sensitivity analysis}

We performed a sensitivity analysis for one tidal (horizontal axis turbine) and one wave energy device (point absorber) in order to identify the model parameters that have the biggest influence on environmental impacts. Each parameter of the model was varied by $\pm 50 \%$ and the resulting variation of the environmental impacts was calculated for each impact category.

In total, 15 parameters have a big influence on the results, i.e. varying the parameter by $\pm 50 \%$ led to a change of over $5 \%$ in at least one environmental impact category (Table 6). Depending on device type, the weight of various subcomponents (e.g. nacelle, frequency converter, gravity base) has a great influence on the results. Naturally, parameters affecting the use phase have a significant influence, e.g. a $50 \%$ decrease in lifetime will increase environmental impact by about 98 to $100 \%$.

A sensitivity analysis was also carried out for the type of steel modelled, since the use of steel contributes significantly to the LCA results. In the base case, it was assumed that stainless steel is used in all parts of the device (Table 2). The alternative considered in the sensitivity analysis is finished cold-rolled coil steel (Thinkstep 2015b). This carbon steel shows lower environmental impacts per kilogram (1 to $85 \%$ less than the stainless steel modelled, depending on the impact category). The LCA results for carbon steel for the horizontal axis turbine and the point absorber showed that the potential environmental impacts would be much lower (by 47 to $99 \%$

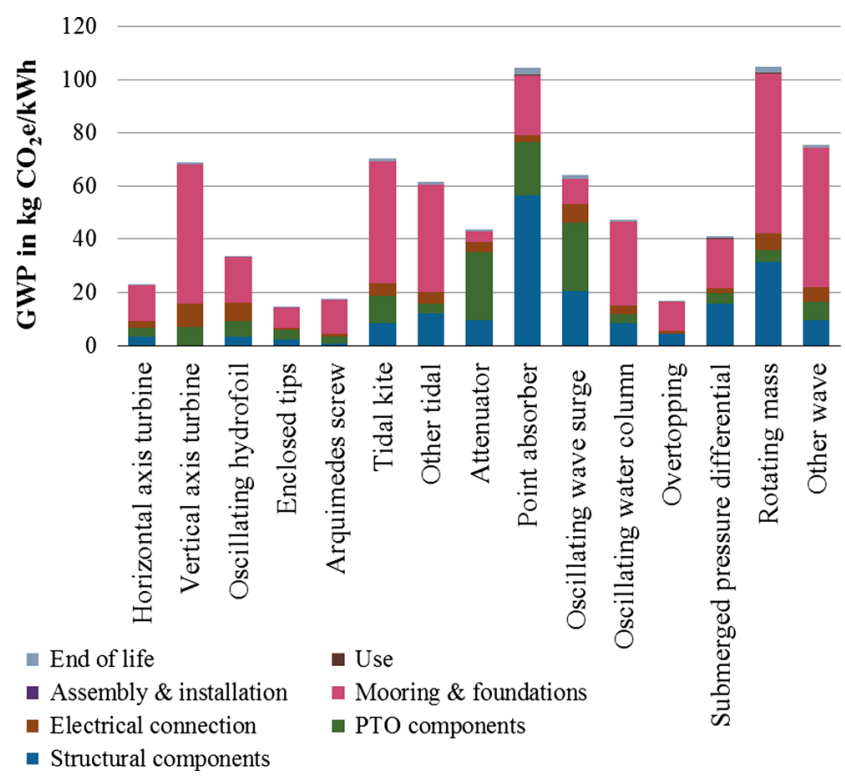

Fig. 10 Global warming potential according to life cycle step 
Table 6 Range of changes in environmental impacts across impact categories for parameters; the model shows greatest sensitivity in percentage related to a change of the parameter by $50 \%$

\begin{tabular}{|c|c|c|c|c|}
\hline Life cycle step & Component & Parameter & Horizontal axis turbine & Point absorber \\
\hline \multirow[t]{6}{*}{ Assembly } & \multirow[t]{3}{*}{ Structural component } & Weight nacelle & $0.75-5.60$ & n.a. \\
\hline & & Weight float & n.a. & $1.44-14.82$ \\
\hline & & Weight other & n.a. & $3.60-20.39$ \\
\hline & \multirow[t]{3}{*}{ PTO component } & Weight frequency converter & $0.26-9.90$ & $0.18-6.53$ \\
\hline & & Weight control system & n.a. & $0.22-7.71$ \\
\hline & & Weight auxiliaries & $0.48-18.29$ & $0.57-20.11$ \\
\hline \multirow[t]{6}{*}{ Installation } & \multirow[t]{4}{*}{ Mooring and foundations } & Weight of lattice support tower & $0.86-8.98$ & n.a. \\
\hline & & Weight of pontoon & n.a. & $0.55-6.24$ \\
\hline & & Weight of gravity base & $2.16-18.77$ & $0.57-5.09$ \\
\hline & & Weight of pile & $1.18-12.40$ & n.a. \\
\hline & \multirow[t]{2}{*}{ Electrical connection } & Weight of cable & $0.00-10.11$ & n.a. \\
\hline & & Weight of connector & $0.06-8.85$ & n.a. \\
\hline \multirow[t]{3}{*}{ Use } & \multirow[t]{3}{*}{ n.a. } & Nominal capacity & 100.00 & 100.00 \\
\hline & & Capacity factor & 100.00 & 100.00 \\
\hline & & Lifetime & $98.87-100.00$ & $98.49-100.00$ \\
\hline Assembly, installation and EOL & Steel & Carbon steel $^{\mathrm{a}}$ & $1.00-53.00$ & $1.00-54.00$ \\
\hline
\end{tabular}

n.a. not applicable

${ }^{a}$ In the case of the sensitivity analysis for steel, it was assumed that $100 \%$ of stainless steel (see Table 2 ) is replaced with finished rolled coil steel

for the horizontal axis turbine and 46 to $99 \%$ for the point absorber, depending on impact category). Thus, the assumptions for the base case are very much a simplification and might be considered as representing a worst-case scenario.

\subsection{LCA results: scenarios}

We drew up a number of scenarios (Table 7) to model potential improvements in life cycle environmental impact, reflecting the importance of individual parameters or environmental hot spots (see Section 4.3) and the ways in which technology developers can change such device- and projectspecific parameters. The horizontal axis turbine was again chosen to exemplify results for tidal energy devices and the point absorber for wave energy devices. We modelled the scenarios shown in Table 7. The bars in Fig. 11 give the range of environmental impacts as compared with the baseline scenario over all impact categories. One must keep in mind that the results are indicative and to some extent hypothetical. For example, higher capacity factors might be achieved only by changes in device design that also affect environmental impacts from manufacturing, which could offset some of the potential environmental gains. Such effects have not been taken into account in this study but represent an interesting field to pursue in future assessments.

If technology developers could increase capacity factors to the maximum values stated in Carlsson (2014), the environmental impacts of horizontal axis turbines and point absorbers could be reduced to 76 and $56 \%$, respectively, for all impact categories (Fig. 11). Similarly, a $50 \%$ longer device lifetime could reduce the life cycle environmental impacts of both devices by $33 \%$ (for all impact categories), given that almost

Table 7 Scenarios modelled

\begin{tabular}{|c|c|c|}
\hline Scenario & Description & Assumptions \\
\hline $\begin{array}{l}\text { Increased } \\
\text { efficiency }\end{array}$ & Higher capacity factor & CF of $45 \%$ instead of $34 \%$ for tidal and $36 \%$ instead of $20 \%$ for wave \\
\hline $\begin{array}{l}\text { Increased } \\
\text { durability }\end{array}$ & Higher lifetime & Lifetime of 30 years instead of 20 years \\
\hline $\begin{array}{l}\text { Other mooring and } \\
\text { foundations }\end{array}$ & $\begin{array}{l}\text { Using mooring lines instead of } \\
\text { foundations }\end{array}$ & $\begin{array}{l}\text { No piles, pontoon and support towers used for mooring but only anchors, mooring lines and } \\
\text { gravity base. Values for average tidal/wave device used }\end{array}$ \\
\hline $\begin{array}{l}\text { Moving further } \\
\text { offshore }\end{array}$ & $\begin{array}{l}\text { Higher ocean energy resources but } \\
\text { longer cable connection }\end{array}$ & $\begin{array}{l}\text { Average distance from shore is about } 2120 \mathrm{~m} \text { for horizontal axis turbines and } 260 \mathrm{~m} \text { for } \\
\text { point absorbers. An increased distance of } 10 \mathrm{~km} \text { is assumed in the scenario, allowing for } \\
\text { reaching maximum capacity factors (see above, } 45 \text { and } 36 \% \text { for tidal and wave energy } \\
\text { devices, respectively) }\end{array}$ \\
\hline
\end{tabular}


Fig. 11 Range of environmental impacts over all impact categories relative to baseline. a Horizontal axis turbines. b Point absorbers

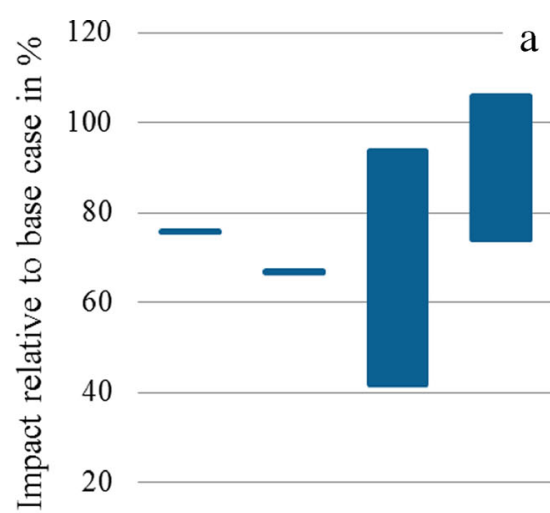

120

b

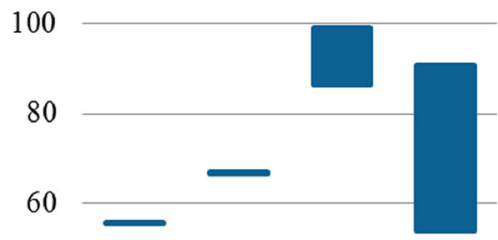

40

20

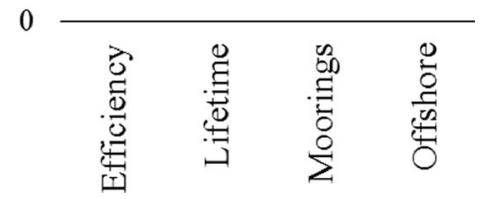

all impacts stem from assembly, installation and end of life and almost none occur during the use phase (Figs. 9 and 10).

The scenario for a change in mooring and foundations suggests that environmental impacts can be reduced for all impact categories. Reductions range from 6 to $58 \%$ for horizontal axis turbines and from 1 to $14 \%$ for point absorbers. The reduction potential for tidal energy devices is higher since they use heavier foundation systems (e.g. gravity bases) than wave energy devices. In the calculations, we did not take into account whether local (wave/tidal current climate) and devicespecific circumstances allowed for a change of mooring and foundation system. Still, considering the large contribution that mooring and foundations make to environmental impacts, even small improvements will help to reduce overall impact.

The fourth scenario analysed the effects of moving devices further offshore, allowing for the use of greater ocean energy resources. This increases efficiency, but the gains in terms of environmental impact are offset by the longer cable connections to be installed in the sea. For point absorbers, there are still net environmental benefits for all impact categories, mainly thanks to high efficiency gains (Fig. 11). For horizontal axis turbines, benefits can be seen for all environmental impacts except freshwater eutrophication and freshwater ecotoxicity. Assumed increases in efficiency (capacity factor between 34 and $45 \%$ ) do not counterbalance additional impacts from the cable connection.

Another scenario we considered was the use of lightweight materials such as composites and aluminium. This could involve greater specific environmental impacts per kilogram of material but also a possible reduction in impacts due to the lower mass of material used. However, there are a number of uncertainties around this scenario, e.g. how much steel might be replaced and the extent to which the structural weight could be reduced. Also, the 'lightweighting' of ocean energy devices

Table 8 Life cycle impact assessment results from literature and this study

\begin{tabular}{|c|c|c|c|c|}
\hline Device type & Impact category & Unit & Literature & This study \\
\hline \multirow[t]{4}{*}{ Attenuator } & Global warming & $\mathrm{g} \mathrm{CO}_{2}$-eq./kWh & $22.8^{\mathrm{a}}-29.8^{\mathrm{b}}$ & 43.7 \\
\hline & Ozone depletion & g CFC-11 eq./kWh & $2.3^{\mathrm{b}}$ & 1.8 \\
\hline & Freshwater eutroph. & $\mathrm{mg} P$ eq./kWh & $9.84^{\mathrm{b}}$ & 0.16 \\
\hline & Marine eutroph. & mg $\mathrm{N}$ eq./kWh & $21.0^{\mathrm{b}}$ & 10.0 \\
\hline Oscillating wave surge & Global warming & $\mathrm{g} \mathrm{CO}_{2}$-eq. $/ \mathrm{kWh}$ & $25^{\mathrm{c}}$ & 64 \\
\hline \multirow[t]{2}{*}{ Point absorber } & Global warming & $\mathrm{g} \mathrm{CO}_{2}$-eq./kWh & $39-126^{\mathrm{d}}$ & 104.5 \\
\hline & Ozone depletion & g CFC-11 eq./kWh & $1.48-4.58^{\mathrm{d}}$ & 4.2 \\
\hline Horizontal axis turbine & Global warming & $\mathrm{g} \mathrm{CO}_{2}$-eq./kWh & $15-20^{\mathrm{e}}$ & 23.1 \\
\hline
\end{tabular}

\footnotetext{
${ }^{\text {a }}$ Parker et al. (2007)

b Thomson et al. (2011)

${ }^{\mathrm{c}}$ Walker and Howell (2011)

${ }^{\mathrm{d}}$ Dahlsten (2009)

${ }^{\mathrm{e}}$ Douglas et al. (2008)
} 
does not currently seem possible, for economic reasons. Due to the uncertainties, the results of this scenario cannot be considered robust enough for a solid conclusion; this might be analysed in a further study.

\section{Discussion and conclusions}

The results of this analysis have shown that there is still considerable divergence in design options for ocean energy (especially wave energy) devices, as also stated in Magagna and Uihlein (2015). There are great variations in weight/power ratios, with specific device weights varying by almost an order of magnitude (from about 470 to $3860 \mathrm{~kg} / \mathrm{kW}$ ). Compared with other renewable energy technologies, ocean energy devices seem to demand quite a high input of materials per installed capacity. For example, according to Krauter (2006), photovoltaic systems weigh 330 to $360 \mathrm{~kg} / \mathrm{kW}$ and wind turbines about 340 to $770 \mathrm{~kg} / \mathrm{kW}$ (Guezuraga et al. 2012). Of course, the material intensity of ocean energy devices can be reduced when they are deployed in arrays, since they can then share some components (e.g. cable connection to the shore, foundation systems). The high power density of tidal current or waves, for example, which in principle allows high efficiencies, also places high demands on devices in terms of reliability and survivability and thus in turn on material inputs.

As mentioned above, most LCAs on ocean energy have focused on energy use and carbon dioxide emissions, to the exclusion of other environmental impact categories. The results of the LCA for the base cases for GHG emissions are in line with the results from previous studies (Table 8). Greater deviations were found for other impact categories, such as eutrophication, possibly, because our impact assessment models differed from those used in previous studies.

We concur with all previous studies that contain and disclose detailed information on the spread of impacts across life cycle phases (e.g. Walker and Howell 2011) in finding that the main environmental impacts from ocean energy devices from an LCA perspective are due to materials use, while installation, maintenance and operation do not show significant impacts.

Comparison with other renewables showed that energy and carbon intensity levels would be similar to those of large wind turbine installations (Walker and Howell 2011). For example, average GHG emissions for electricity production from other renewables are about 34 and $50 \mathrm{~g} \mathrm{CO}_{2}$-eq. $/ \mathrm{kWh}$ for wind and solar PV, respectively (Nugent and Sovacool 2014), 20-80 g $\mathrm{CO}_{2}$-eq./kWh for concentrated solar power (Burkhardt et al. 2012) and 40-80 g CO$_{2}$-eq./kWh for geothermal (Frick et al. 2010). Ocean energy devices thus offer the potential to limit environmental impacts to levels associated with other renewable technologies, especially as regards global warming.
Certainly, they can contribute to a more sustainable energy supply as compared with fossil fuels (Lewis et al. 2011).

Environmental impacts from ocean energy devices can be further reduced, as the scenario calculations have shown (Section 4.3). Developers are already focusing on improvements such as increased efficiency, durability and reliability and better mooring systems, in order to advance ocean energy technologies and further reduce costs (Magagna and Uihlein 2015). One approach to increasing efficiency and reducing environmental impacts is to move further offshore in order to deploy devices in areas with greater resources (e.g. higher wave energy). However, environmental benefits could be offset by the longer cable lengths needed, so this option needs to be examined carefully.

In the future, ocean energy devices will also be installed in arrays or even ocean energy farms. This will clearly reduce the environmental impacts per kilowatt-hour of electricity produced, since some components (e.g. cable, electrical hubs, substation) could be shared. Future LCAs should thus focus on whole arrays of ocean energy devices. Since ocean energy resources are variable (although very predictable, e.g. in the case of tidal currents), studies taking into account the fluctuations in electricity production would also be very useful for assessing the environmental benefits of ocean energy.

\section{Compliance with ethical standards}

Disclaimer The views expressed in this paper are those of the writer only and may in no circumstances be regarded as representing an official position of the European Commission.

Open Access This article is distributed under the terms of the Creative Commons Attribution 4.0 International License (http:// creativecommons.org/licenses/by/4.0/), which permits unrestricted use, distribution, and reproduction in any medium, provided you give appropriate credit to the original author(s) and the source, provide a link to the Creative Commons license, and indicate if changes were made.

\section{References}

Anonymous (2011) Submarine cable solutions, laying and challenges. General Cable, Highland Heights

Burkhardt JJ, Heath G, Cohen E (2012) Life cycle greenhouse gas emissions of trough and tower concentrating solar power electricity generation. J Ind Ecol 16:S93-S109

Carlsson J (2014) Energy technology reference indicator (ETRI) projections for 2010-2050. Publications Office of the European Union, Luxembourg

Dahlsten H (2009) Life cycle assessment of electricity from wave power. Swedish University of Agricultural Sciences

Dalton G, Madden D, Daly MC (2014) Life cycle assessment of the wavestar. In: 2014 ninth international conference on ecological vehicles and renewable energies (EVER). IEEE, Monte Carlo. pp 1-9

Douglas CA, Harrison GP, Chick JP (2008) Life cycle assessment of the Seagen marine current turbine. Proc Inst Mech Eng Part M J Eng Marit Environ 222:1-12 
Ecoinvent (2007) Ecoinvent data v2.0. Ecoinvent, Dübendorf

Esteban M, Leary D (2012) Current developments and future prospects of offshore wind and ocean energy. Appl Energy 90:128-136

Eyerer P (ed) (1996) Ganzheitliche Bilanzierung. Springer, Berlin

Falcão AF de O (2010) Wave energy utilization: a review of the technologies. Renew Sustain Energy Rev 14:899-918

Frick S, Kaltschmitt M, Schröder G (2010) Life cycle assessment of geothermal binary power plants using enhanced low-temperature reservoirs. Energy 35:2281-2294

Guezuraga B, Zauner R, Pölz W (2012) Life cycle assessment of two different 2 MW class wind turbines. Renew Energy 37:37-44

Hauschild MZ, Goedkoop M, Guinée J et al (2012) Identifying best existing practice for characterization modeling in life cycle impact assessment. Int J Life Cycle Assess 18:683-697

Heck T (2007) Ecoinvent report no. 6-XIV. Wärme-Kraft-Kopplung. Data v2.0. Ecoinvent, Villigen

Krauter SCW (2006) Solar electric power generation. Springer, Heidelberg

Lewis A, Estefen S, Huckerby J et al (2011) Ocean energy. In: Edenhofer $\mathrm{O}$, Pichs-Madruga R, Sokona Y et al (eds) IPCC special report on renewable energy sources and climate change mitigation. Cambridge University Press, Cambridge, pp 497-533

Lopez J, Ricci P, Villate JL, et al. (2010) Preliminary economic assessment and analysis of grid connection schemes for ocean energy arrays. In: 3rd international conference on ocean energy. Bilbao

Magagna D, Uihlein A (2015) Ocean energy development in Europe: current status and future perspectives. Int J Mar Energy 11:84-104

Nugent D, Sovacool BK (2014) Assessing the lifecycle greenhouse gas emissions from solar PV and wind energy: a critical meta-survey. Energy Policy 65:229-244
Parker RPM, Harrison GP, Chick JP (2007) Energy and carbon audit of an offshore wave energy converter. Proc Inst Mech Eng Part A J Power Energy 221:1119-1130

Raventos A, Simas T, Moura A, Harrison G, Thomson C, Dhedin JF (2010) Life Cycle Assessment for marine renewables. EquiMar (Equitable Testing and Evaluation of Marine Energy Extraction Devices in terms of Performance, Cost and Environmental Impact). Deliverable D6.4.2. Grant Agreement number: 213380. http://tethys.pnnl.gov/sites/default/files/publications/EquiMar_D6. 4.2.pdf

Sullivan JL, Burnham A, Wang MQ (2013) Model for the part manufacturing and vehicle assembly component of the vehicle life cycle inventory. J Ind Ecol 17:143-153

Thinkstep (2015a) Gabi 6.4 LCA software. Leinfelden-Echterdingen

Thinkstep (2015b) Gabi professional database, SP 27. LeinfeldenEchterdingen

Thomson RC, Harrison GP, Chick JP (2011) Full life cycle assessment of a wave energy converter. In: IET conference on renewable power generation (RPG 2011). IET, Edinburgh. pp 63-63

Uihlein A, Magagna D (2015) A review of the current state of research in the area of ocean energy. Renew Sust Energ Rev 58:1070-1081. doi: 10.1016/j.rser.2015.12.284

Uihlein A, Magagna D, Raventos A, Silva M (2015) Wave and tidal energy in Europe: assessing present technologies. In: 11th European wave and tidal energy conference series. Nantes

Walker S, Howell R (2011) Life cycle comparison of a wave and tidal energy device. Proc Inst Mech Eng Part M J Eng Marit Environ 225: 325-337

Zimmermann T (2012) Parameterized tool for site specific LCAs of wind energy converters. Int J Life Cycle Assess 18:49-60 